\title{
THE EMERGING NEED FOR ADOLESCENT- FOCUSED HIV CARE IN SOUTH AFRICA
}

\author{
H B Jaspan ${ }^{1}, M D, P h D, F A A P$ \\ $\mathbf{R} \mathbf{L i}^{\mathbf{2}}$, MPhil \\ L Johnson $^{\mathbf{3}}, P h D, A I A$ \\ L-G Bekker ${ }^{1}, M B C h B, P h D, F C P$ \\ ${ }^{I}$ Desmond Tutu HIV Centre, Institute of Infectious Diseases and Molecular Medicine, University of Cape Town \\ ${ }^{2}$ Centre for Social Science Research, University of Cape Town \\ ${ }^{3}$ Centre for Actuarial Research, University of Cape Town
}

Before the widespread introduction of antiretroviral therapy (ART), most perinatally infected children did not survive beyond the first 2 years of life. ${ }^{1}$ With treatment, HIV-positive children are living longer. In the developed world, where HAART has been widely available since 1996, survival of perinatally infected children into adolescence is now the norm. Of a French cohort of perinatally infected children born before 1993,58\% were still alive and receiving HIV care 13 years later. $^{2}$ In the UK the proportion of HIV-infected children in care aged 10 - 19 years increased from $11 \%$ to $44 \%$ between 1996 and 2005. ${ }^{3}$ As HAART becomes increasingly available in South Africa, we can expect similar trends.

In addition to a growing population of vertically infected adolescents in South Africa, youth are among those at greatest risk of HIV acquisition. ${ }^{4}$ Uptake of voluntary counselling and testing is low in adolescents, with only $20 \%$ of youth ever having had an HIV test ${ }^{5}$ and even fewer engaging with the health care system for CD4 monitoring and health maintenance. At youth centres in the Cape Metropole, catering to 15 - 25year-olds only, testing uptake is $85 \%$ and two-thirds go on to receive CD4 counts (Karen Jennings, personal communication). Although most horizontally infected adolescents are not in immediate need of treatment, they could benefit from care and certainly from knowledge of their HIV status.

Mathematical models can be used to project the growth in the numbers of adolescents needing antiretroviral treatment in South Africa. The ASSA2003 AIDS and Demographic model ${ }_{1}^{6,7}$ updated to reflect recent data on prevention of mother-to-child transmission ${ }^{8}$ and paediatric survival on antiretroviral treatment, ${ }^{9}$ estimates that by the middle of 2008, approximately 6000 youth aged $10-19$ were receiving highly active antiretroviral therapy (HAART) and a further 6000 met entry criteria for HAART. If it is assumed that South Africa meets the National Strategic Plan target of providing antiretroviral treatment to $80 \%$ of all individuals pro- gressing to $\operatorname{AIDS}^{10}{ }^{10}$ the number of adolescents receiving antiretroviral treatment can be expected to increase to 153000 by 2020 . While youth aged $10-19$ accounted for only $1 \%$ of the total number of patients receiving HAART in 2008, this proportion is expected to grow to approximately $5 \%$ by 2020 , mainly as a result of vertically infected children surviving into adolescence. Treatment and care for HIV-positive adolescents will therefore become increasingly important over the next decade. This contrasts with other chronic childhood illnesses such as rheumatic heart disease, where the prevalence is declining. For example an estimated 46 cases of acute rheumatic fever were reported in 2002 in adolescents aged $10-19$ years, only some of whom went on to develop rheumatic heart disease. ${ }^{11}$

Adolescent health care is distinct from both paediatric and adult heath care because of the physiological and psychosocial transitions that occur during this period. HIV interferes with these normal developmental processes by delaying physical and intellectual development. In addition, HIV-positive adolescents confront many extra challenges, including concerns about medication regimens, doctors' appointments, life expectancy, social upheaval, disclosure, stigmatisation, transmission of virus to others and the fear of being 'abnormal'. The combination of HIV-related issues that are common to any age group and the extensive and rapid changes of adolescence create an exceptional and formidable challenge for both young people themselves and the adults who care for them.

Providing quality care and treatment for HIV-positive adolescents requires distinct needs to be addressed:

- Young people living with HIV require knowledge and understanding of their HIV status. Disclosure of status at this age is paramount, although often not easy to accomplish. Once aware of their serostatus, adolescents require frank ongoing communication and education to ensure understanding of the implications and acceptance of living with their illness. While often deferred in childhood, disclosure is 
crucial during adolescence as individuals approach cognitive maturity. ${ }^{12}$ Significant adults may need to be guided and supported in this process.

- HIV places multiple stressors on the life of the adolescent, including side-effects from medication, chronic illness, real or perceived stigma, and frequently the death of family members. Young people living with HIV may struggle to achieve mental health. North American research has described high rates of mental disorders among HIV-infected adolescents, although it remains unclear whether these problems are associated with the virus itself or other environmental factors. ${ }^{13}$ Whatever the cause, evidence suggests that young people living with HIV need appropriate psychological services for adjustment and survival of the youth into adulthood. This is particularly important given that mental health status affects HAART adherence and engagement in risky sexual behaviour. ${ }^{14,15}$

- Adolescents need social, emotional, spiritual, and often material support. ${ }^{16}$ Often HIV-infected adolescents are alienated from their peers. ${ }^{17}$ Support groups can provide this support where peers do not. However, such groups cannot replace support for daily living, where additional assistance is often required.

- Because adherence to treatment and treatment programmes is integral for sustaining positive health outcomes, HIV-positive young people need support in managing their treatment. During childhood, caregivers are often heavily involved in their children's daily routines, and provide instrumental help in taking tablets. However, as children grow up, expectations for them to take increasing responsibility for their medication and clinic appointments emerge. Among adolescents adherence is a major problem, and studies suggest that compliance during this period is lower than in other stages of life. ${ }^{18-20}$ This is probably due to disease denial, ${ }_{1}^{21}$ peer pressure and social norms, rebelliousness and risk-taking behaviour, among other reasons. In a local large, private sector, sub-Saharan African programme, where adolescents were treated similarly to adults, the adolescent patients were 1.5 times less likely to be virologically suppressed at one year, due to poorer adherence ${ }^{20}$ Adolescents therefore need targeted interventions that enhance adherence and promote responsible treatment management.

- Finally, young people living with HIV need to learn how to make healthy decisions about reproductive and sexual health. Like their HIV-negative peers, HIV-positive adolescents will be maturing sexually and will have questions about their ability to date and engage in sexual activity. ${ }^{23,24}$ With sexual behaviour comes the potential for unwanted pregnancy, acquisition of other sexually transmitted infections, re-infection with more pathogenic virus, and transmission of the virus to others. The potential costs of unsafe sex are therefore exceptionally high for infected young people and their partners. Young people need age-specific sexual and reproductive health services, and information and counselling to minimise risky sexual behaviour and encourage positive sexual identities. ${ }^{24}$

We are currently in a critical moment of transition, during which the first generation of perinatally infected South African children are navigating their way through adolescence. As numbers increase, we need to plan for their distinct needs. Multidisciplinary adolescentspecific programmes, addressing both the biomedical and the psychosocial aspects of living with HIV, would help prevent young people from falling through the cracks of paediatric or adult-orientated health care services. A few such interventions, such as the National Adolescent Friendly Clinic Initiative, have already been implemented in a number of clinics and hospitals around the country ${ }^{25}$ and should be monitored, evaluated, and expanded.

Adolescent-targeted care is a glaring gap in our health care system, where we have neither specialists nor wards to cater for teenagers with chronic illness. Endocrinologists, cardiologists, oncologists, and other specialities that care for adolescents in South Africa have been struggling with this challenge for years. ${ }^{26,27}$ The HIV epidemic, with its unprecedented numbers and characteristic disease burden in youth, may provide the impetus for the South African medical system to address the specific needs of our adolescent population. Failing to do so may jeopardise the longevity of more than 150000 adolescents requiring HAART in the next decade.

REFERENCES

1. Brahmbhatt $H$, Kigozi $G$, Wabwire-Mangen $F$, et al. Mortality in HIV-infected and uninfected children of HIV-infected and uninfected mothers in rural Uganda. $J$ Acquir Immune Defic Syndr 2006; 41(4): 504-508.

2. Dollfus $\mathrm{C}$, Tabone MD, Trocmé N, Vaudré G, Leverger G. Devenir à l'adolescence des enfants séropositifs au VIH après transmission mère-enfant [Long term outcomes in HIV infected adolescents followed from birth]. Med Mal Infect 2006; 36(9): 479-480.

3. Judd A, Doerholt K, Tookey PA, et al. Morbidity, mortality and response to treatment by children in the United Kingdom and Ireland with perinatally acquired HIV infection during 1996-2006: planning for teenage and adult care. Clin Infect Dis 2007; 45(7): 918-924.

4. Department of Health. National HIV and Syphilis Antenatal Seroprevalence Survey in South Africa 2007. Pretoria, 2008.

5. Shisana 0, Rehle T, Simbayi LC, et al. South African National HIV Prevalence, HIV Incidence, Behavior and Communication Survey. Cape Town: HSRC Press, 2005.

6. Dorrington RE, Johnson LF, Bradshaw D, Daniel T. The Demographic Impact of HIV/AIDS in South Africa. National and Provincial Indicators for 2006. Cape Town: Centre for Actuarial Research, South African Medical Research Council and Actuarial Society of South Africa, 2006. http://www.commerce.uct.ac.za/care

7. Johnson LF, Dorrington RE. Modelling the demographic impact of HIV/AIDS in South Africa and the likely impact of interventions. Demographic Research 2006; 14: $541-574$

8. Barron P, Day C, Monticelli F. The Disrict Health Barometer - Year 2006/07. Health Systems Trust, 2008. http://www.hst.org.za/publications/717 (accessed 22 February 2008)

9. Boulle $A$, Bock $P$, Osler $M$, et al. Antiretroviral therapy and early mortality in South Africa. Bull World Health Organ 2008; 86(9): 678-687.

10. Department of Health. HIV and AIDS and STI Strategic Plan for South Africa 2007-2011. 2007. http://www.doh.gov.za/docs/misc/stratplan-f.html (accessed 23 March 2007).

11. Department of Health, Statistical Notes, Feb 2002. www.doh.gov.za/facts/statsnotes/2002/rheumatic.pdf (accessed 19 November 2009).

12. Abadia Barrero CE, Larusso MD. The disclosure model versus a developmental illness experience model for children and adolescents living with HIV/AIDS in São Paulo, Brazil. AIDS Patient Care STDs 2006; 20(1): 36-43. 
13. Scharko AM. DSM psychiatric disorders in the context of pediatric HIV/AIDS. AIDS Care 18(5): 441-445.

14. Murphy DA, Durako SJ, Mockicki AB, et al. No change in risk behaviours over time among HIV infected adolescents in care: role of distress. J Adolesc Health 2001; 29(3 suppl 1): $57-63$.

15. Murphy DA, Belzer M, Durako SJ, Sarr M, Wilson CM, Muenz LR. Longitudinal antiretroviral adherence among adolescents infected with human immunodeficiency virus. Arch Pediatr Adolesc Med 2005; 159(8): 767-770.

16. Lam PK, Naar-King S, Wright K. Social support and disclosure as predictors of mental health in HIV-positive youth. AIDS Patient Care STDs 2007; 21(1): 20-29.

17. Li $R$, Jaspan $H B$, O'Brien $V$, Rabie $H$ Cotton MF Nattrass $N$. Positive futures: A qualitative study on the needs of adolescents on antiretroviral therapy in South Africa. AIDS Care (in press).

18. Williams $P L$, Storm D, Montepiedra G, et al. Predictors of adherence to antiretroviral medications in children and adolescents with HIV infection. Pediatrics 2006; 118(6): e1745-e1757.

19. Becker SL, Dezii CM, Burtcel B, Kawabata H, Hodder S, et al. Young HIV-infected adults are at greater risk for medication nonadherence. MedGenMed 2002; 4(3): 21.

20. Nachega J, Hislop M, Nguyen $\mathrm{H}$, et al. Antiretroviral therapy adherence, virologic and immunologic outcomes in adolescents compared with adults in Southern Africa. J Acquir Immune Defic Syndr 2009; 51: 65-71.

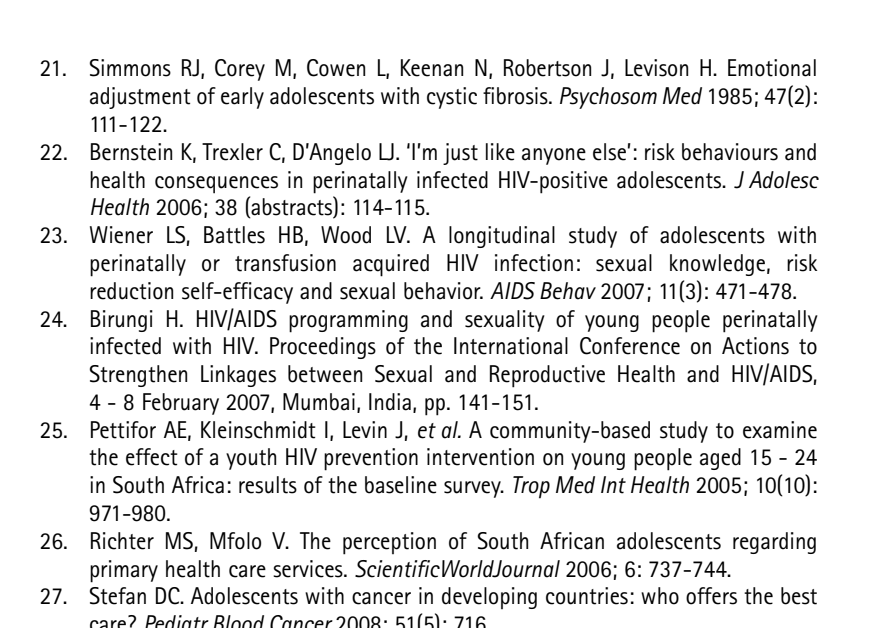

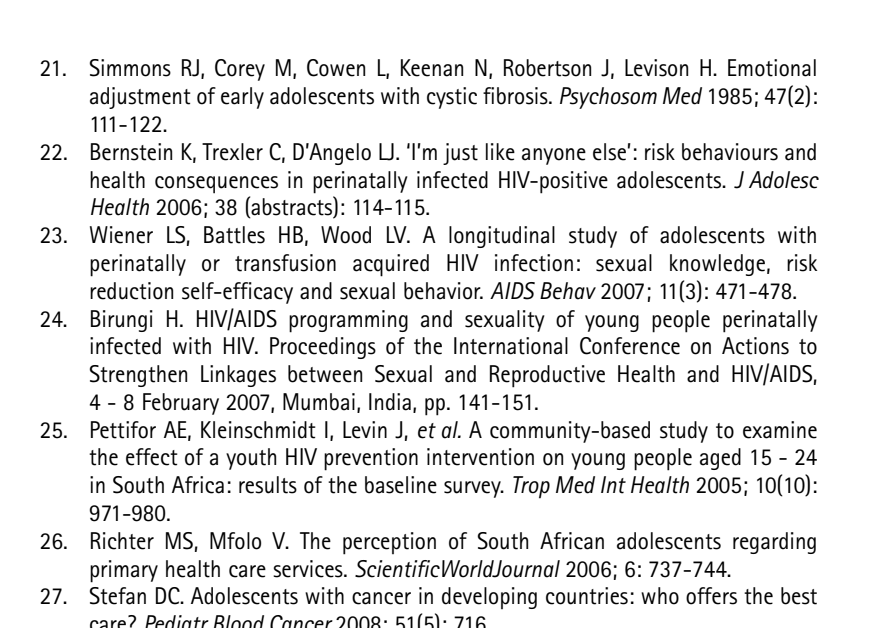

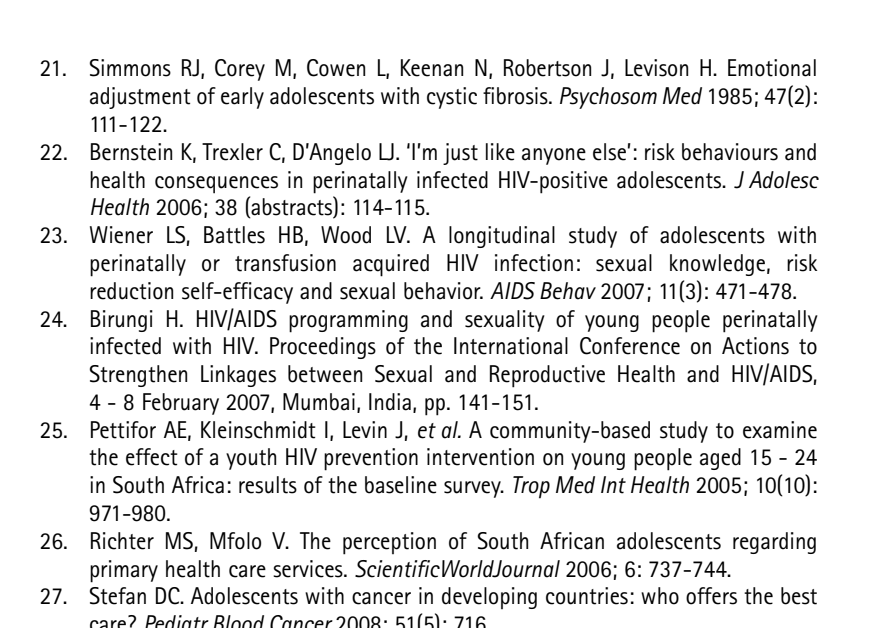

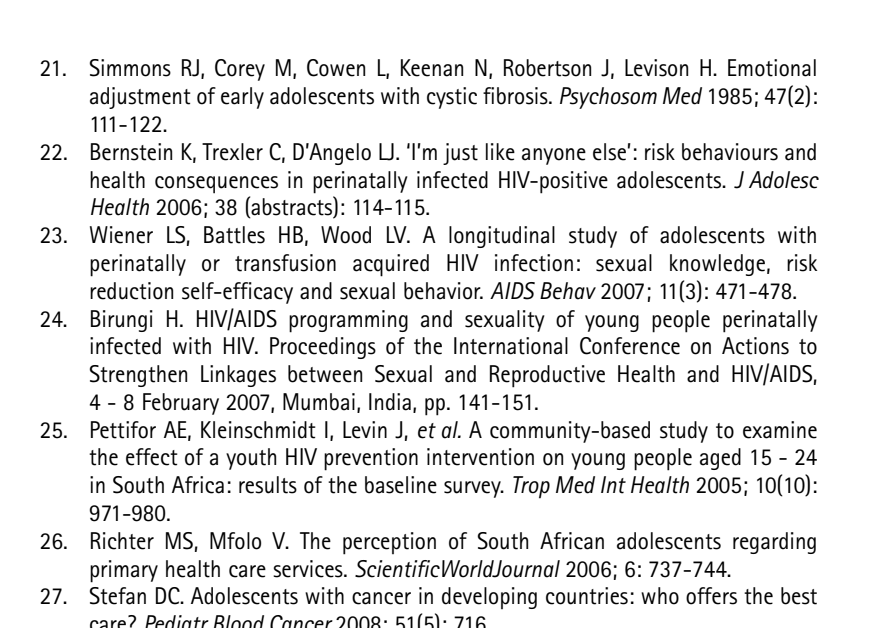

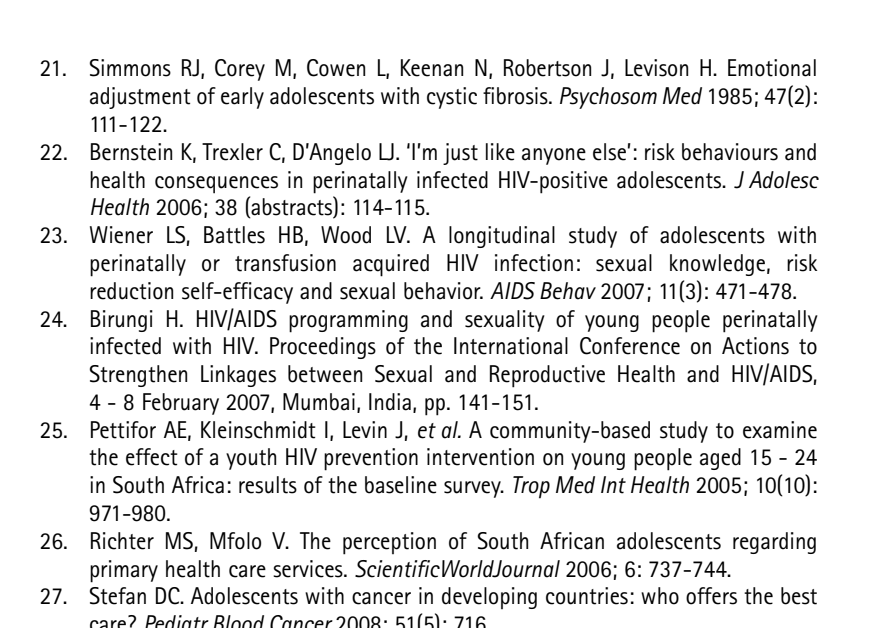

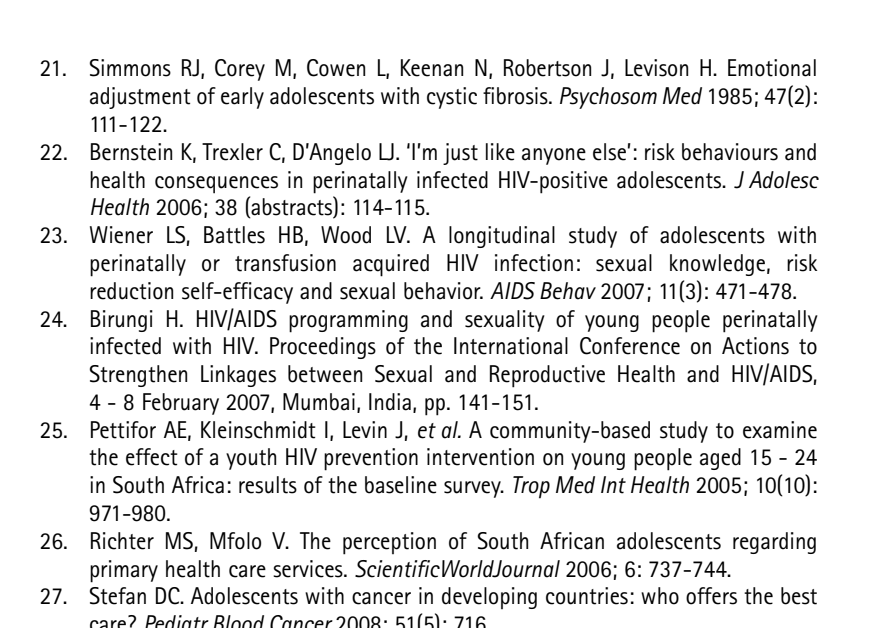

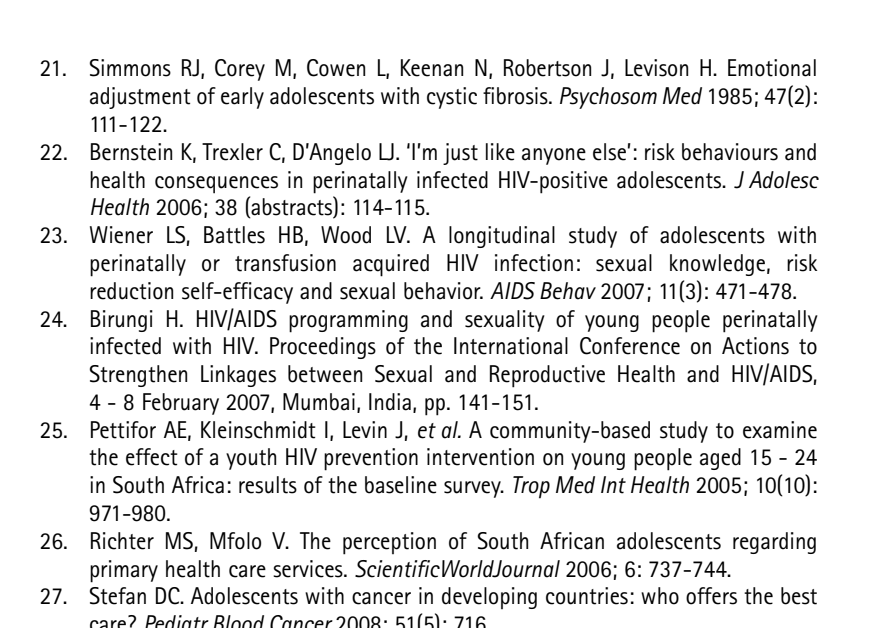

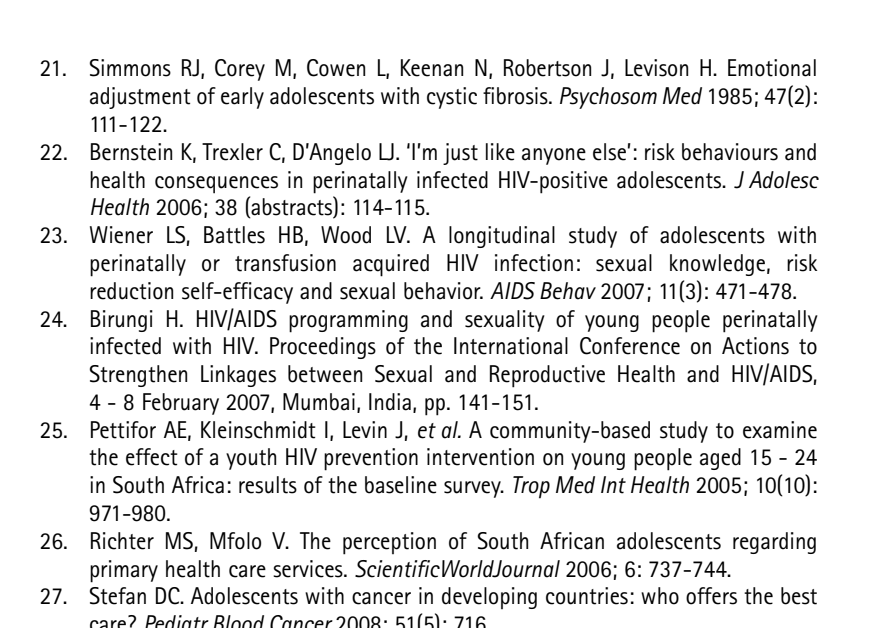

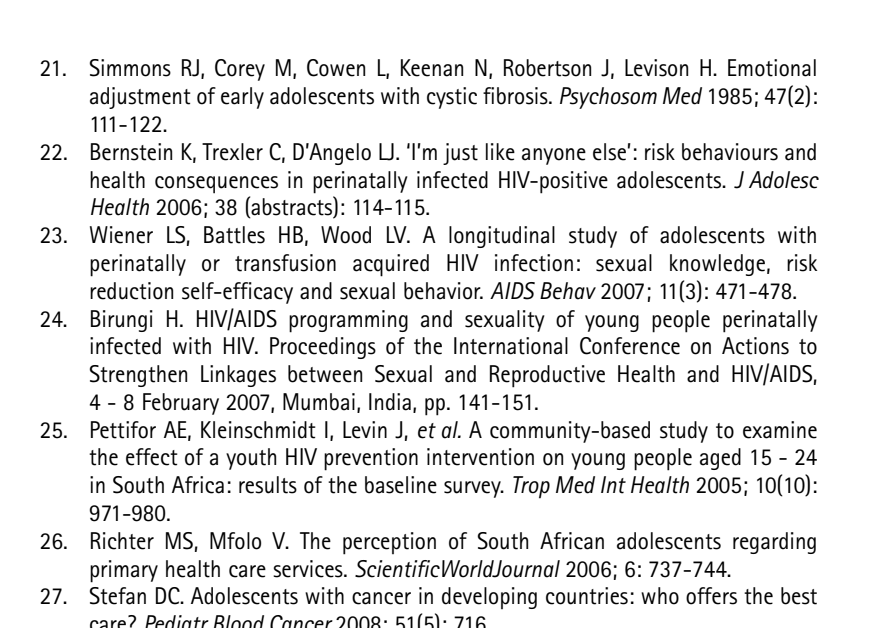

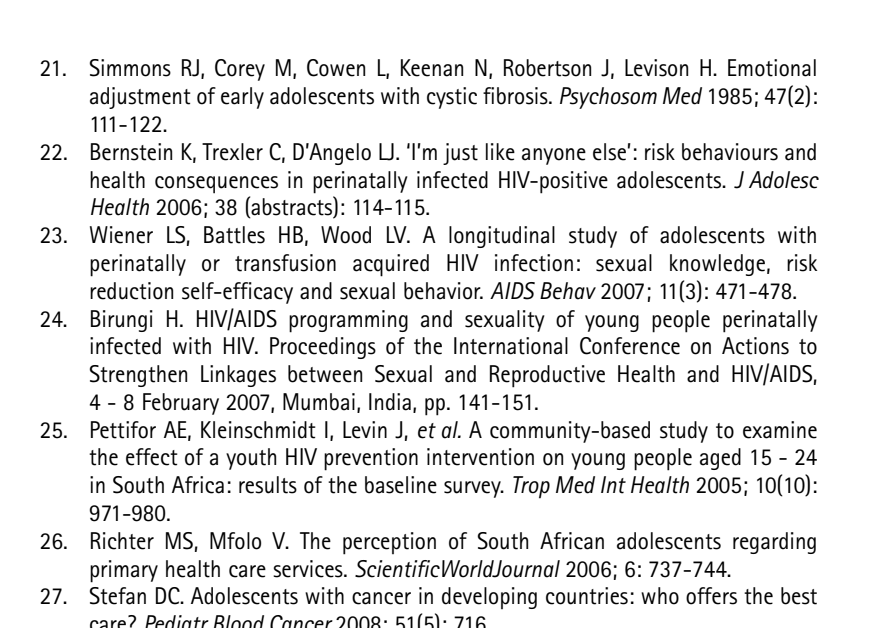

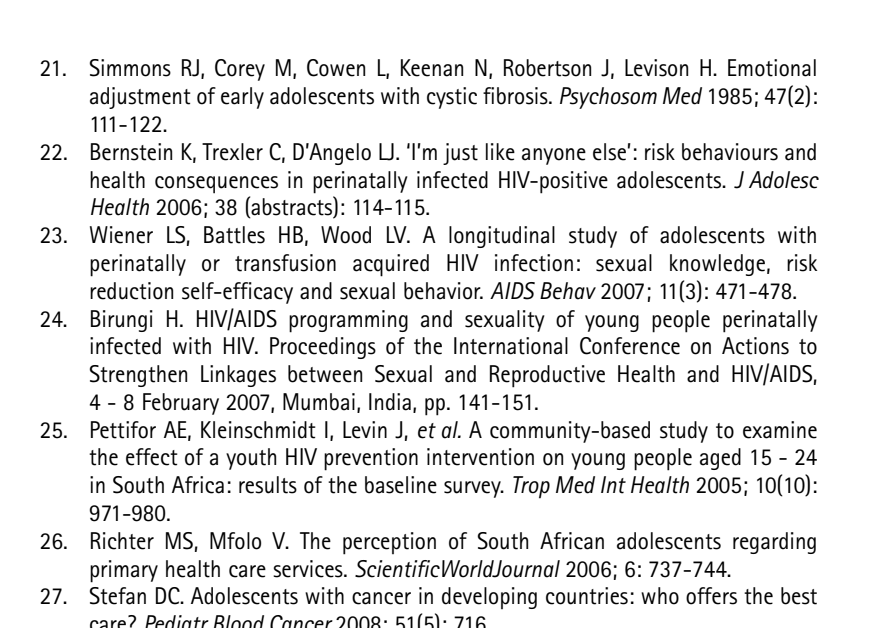

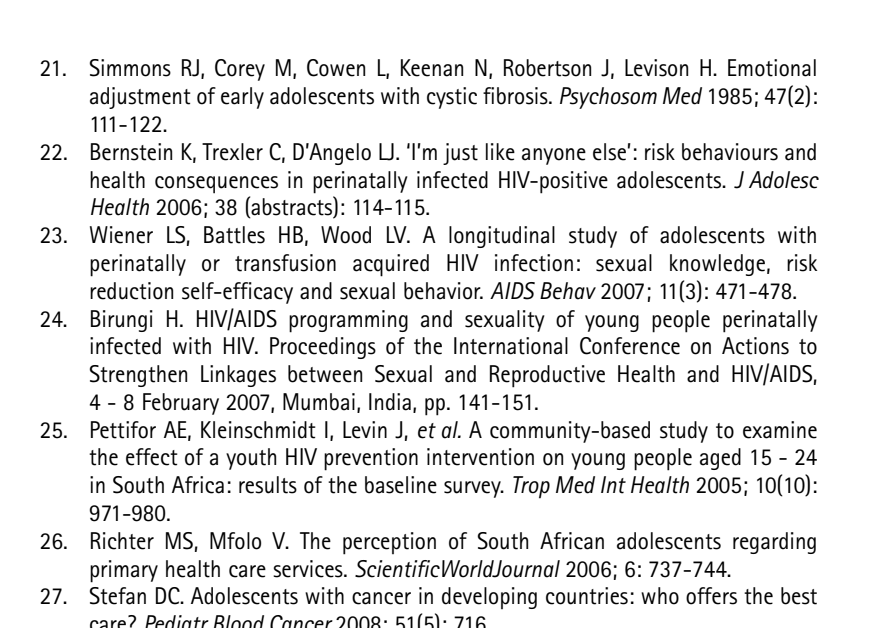

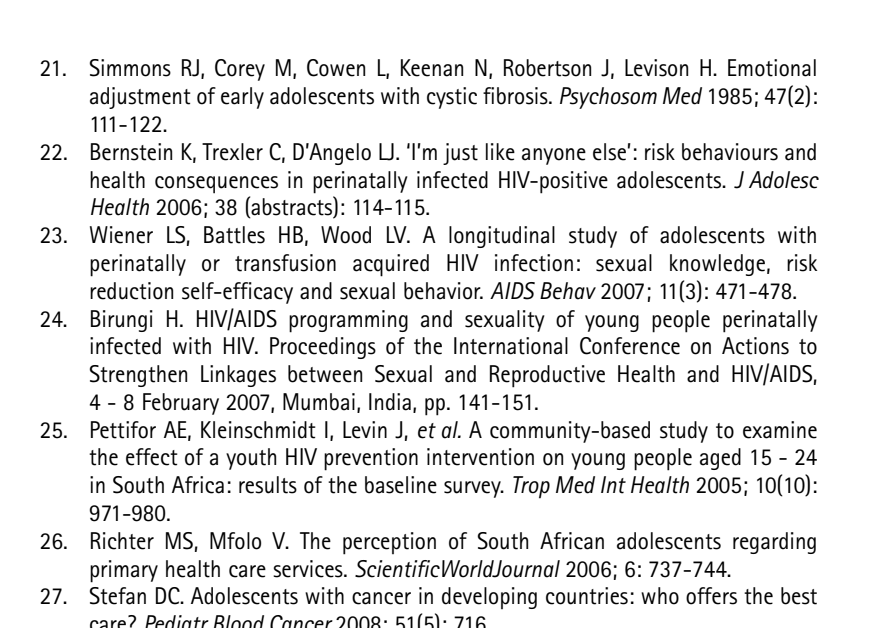

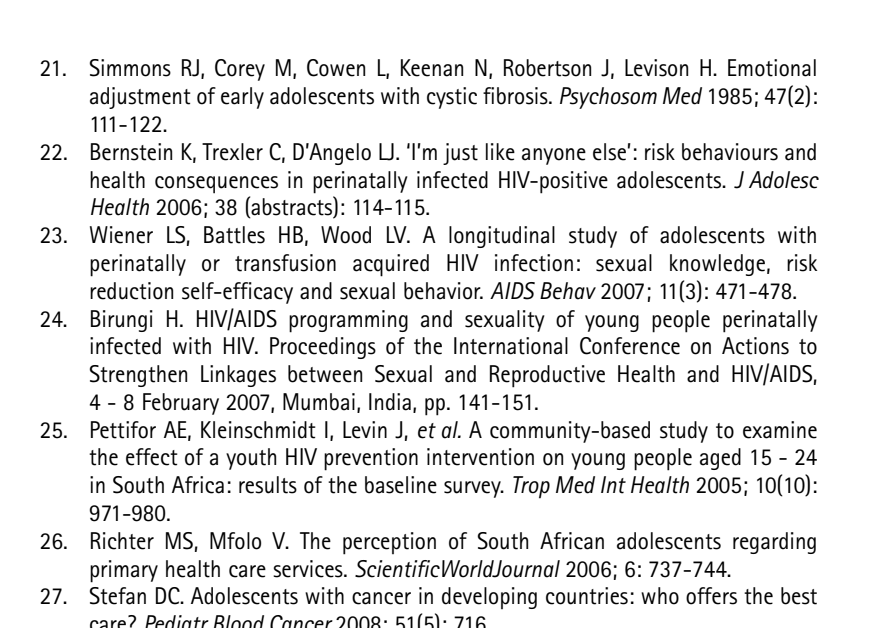

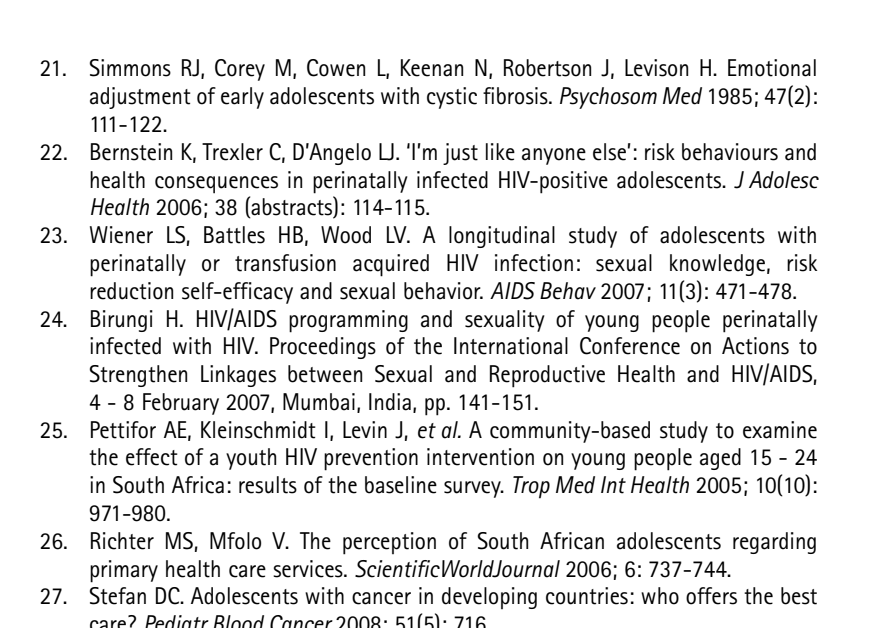

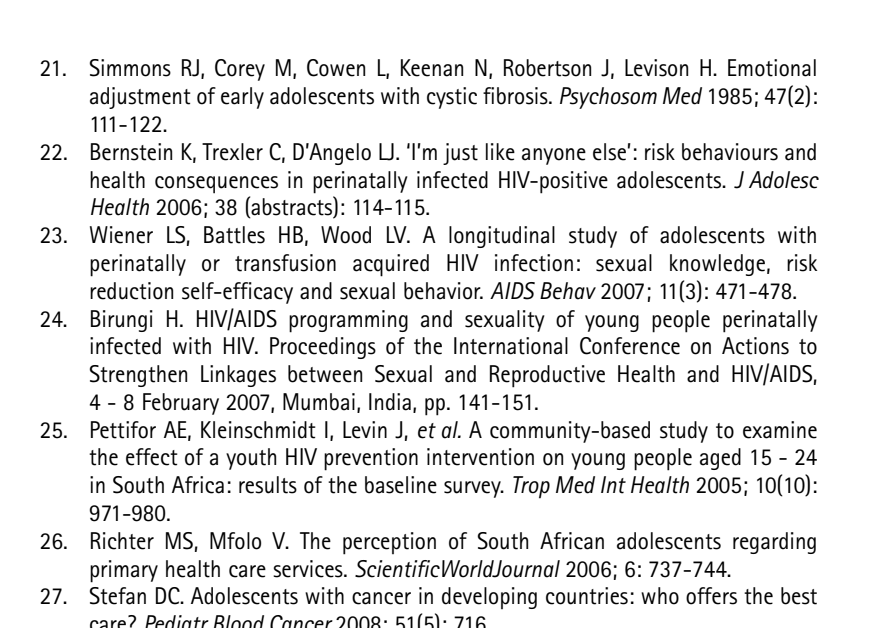

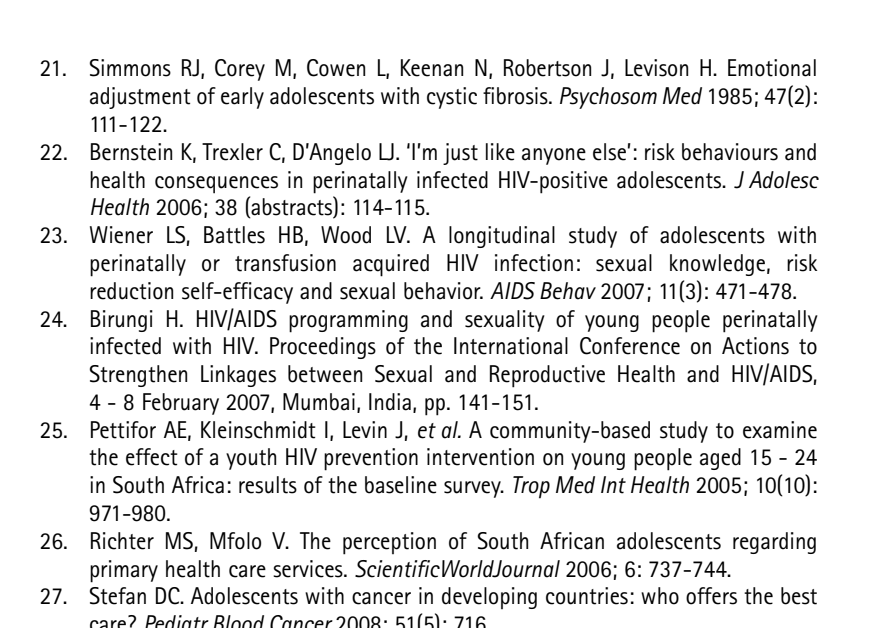

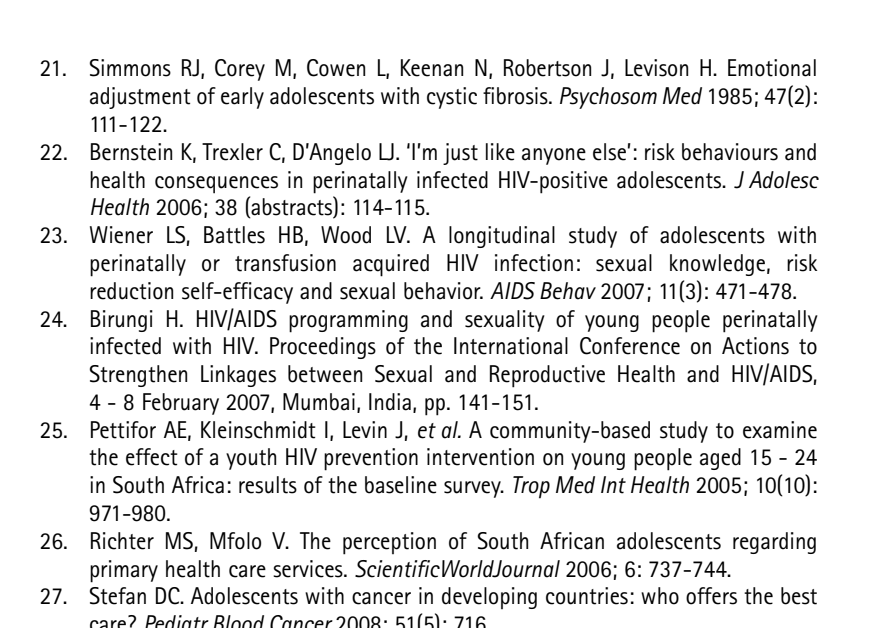

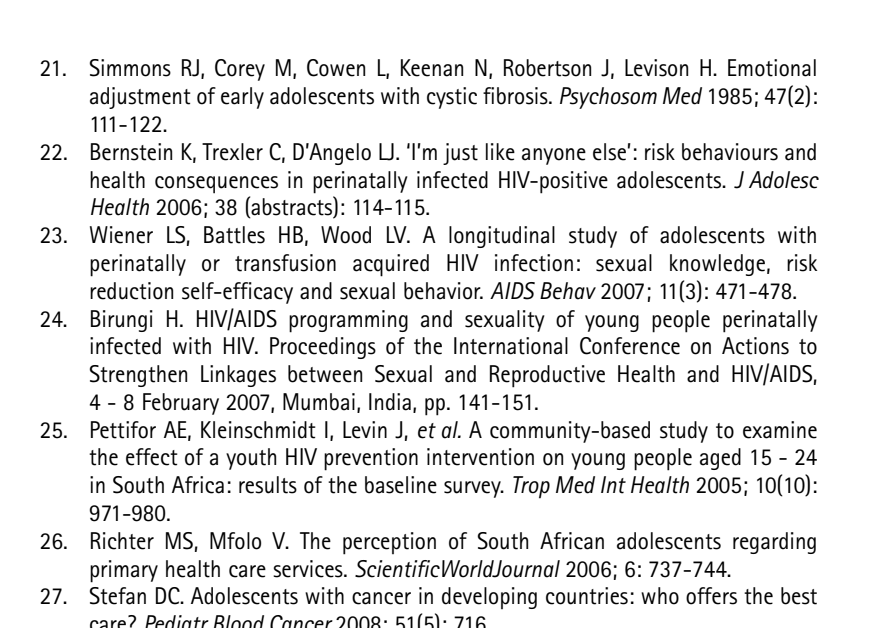

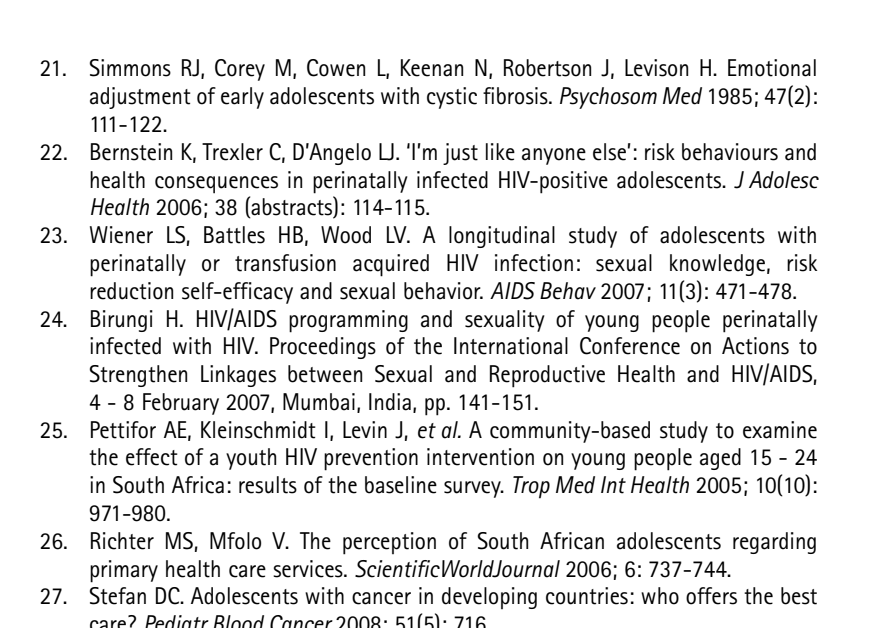

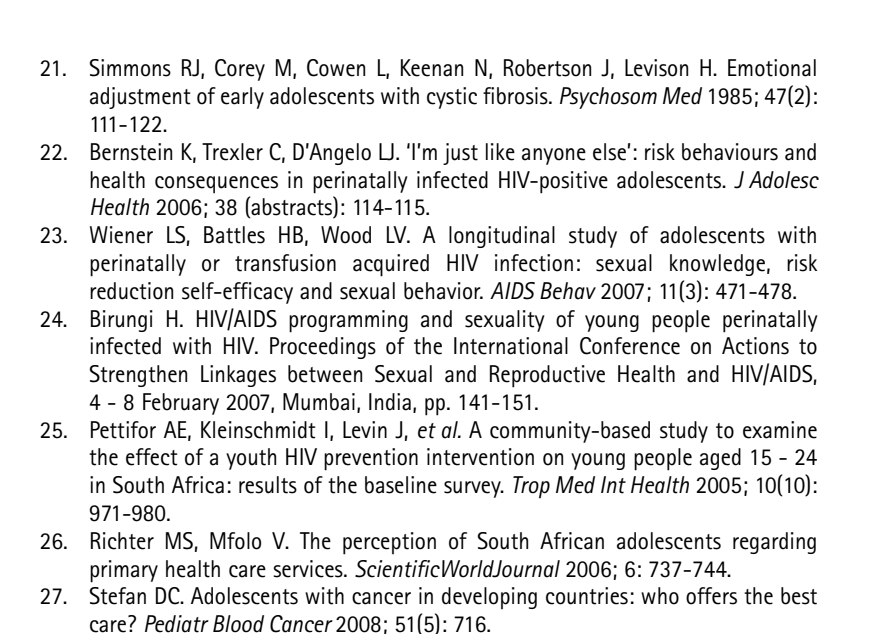

